\title{
Valoração Econômica dos Impactos Ambientais de Tecnologias de Plantio em Região de Cerrados
}

Waldecy Rodrigues ${ }^{1}$

Resumo: A expansão da fronteira agrícola nos Cerrados com a produção agropecuária em larga escala amplia os custos ambientais, porém sua intensidade depende essencialmente da técnica de plantio adotada. O estudo valora economicamente, através do Método Custo-Reposição (MCR), os impactos ambientais de tecnologias de plantio de soja e milho em região de Cerrados. No caso da soja a adoção do plantio direto eleva o custo de produção em $0,47 \%$, mas provoca uma redução de ($81,22 \%$ ) no custo ambiental. No cultivo do milho, os custos de produção do plantio direto são $(-5,92 \%)$ menores do que os referentes ao plantio convencional e provoca uma redução no custo ambiental em (- 29,43\%). Na região específica do estudo os danos ambientais anuais causados pelo plantio convencional foram estimados em $\mathrm{R} \$ 317.213,39$ e no plantio direto de $\mathrm{R} \$ 81.375,76$. A adoção do plantio direto nas culturas de soja e milho demonstra sua maior eficácia social pela redução do processo erosivo dos solos e do assoreamento de recursos hídricos.

Palavras-chaves: Método custo-reposição, custos ambientais, commodities e meio ambiente.

\section{Classificação JEL: Q51}

${ }^{1}$ Doutor (UnB). Professor do Curso de Economia da Universidade Federal do Tocantins. E-mail: waldecy@terra.com.br 
Abstract: The expansion of the agricultural border in brazilian savannahas with the farming production in wide scale extends the environmental costs, however it depends essentially on the adopted technique of plantation. The study it evaluates economically, by Replacement Cost Method, the environmental impacts of technologies of soy and corn plantation. In the case of the soy the no tillage raises the cost of production in $0,47 \%$, but it provokes a reduction of $(-81,22 \%)$ in the environmental cost. In the corn, the costs of no tillage are $(-5,92 \%)$ lesser of that conventional tillage and provoke a reduction in the environmental cost in (-29,43\%). In the specific region of the study the annual ambient damages caused by the conventional tillage had been esteem in $R \$ 317,213.39$ and the no tillage of $R \$ 81.375,76$. The adoption of the no tillage in the plantation of soy and corn demonstrates its bigger social effectiveness for the reduction of the erosive process and improvement of the outflow and the quality of the rivers.

Key words: Replacement cost method, environmental costs, commodities and environment.

Jel Classification: Q51 - Valuation of environmental effects

\section{Introdução}

As tecnologias utilizadas pelos produtores rurais em regra são escolhidas por sua eficiência e rentabilidade econômicas. Entretanto, estas opções tecnológicas, ao causarem danos ambientais, afetam negativamente o bem-estar de outros agentes que utilizam os recursos ambientais comuns. Especificamente, a medição dos impactos ambientais dos pacotes tecnológicos disponíveis ao produtor rural trás uma importante contribuição para o debate do dilema existente entre eficiência econômica e eficácia social associado às escolhas técnicas feitas por agentes maximizadores de lucros.

Historicamente, os Cerrados brasileiros, com a expansão da fronteira agrícola na região a partir da década de 1970, passaram a ser sistematicamente ocupados pela produção agropecuária em larga escala. O modelo tecnológico dominante na exploração agrícola nos Cerrados é profundamente dependente de insumos externos (calcário e fertilizan- 
tes) produzidos por grandes indústrias do setor químico. Este modelo representado pela expansão de commodities e suas tradicionais técnicas de plantio são responsáveis por vários impactos ambientais nos solos, nos recursos hídricos e na biodiversidade.

A partir da década de 80 , na região de Cerrados, principalmente devido aos problemas relacionados com a erosão dos solos e a vinda de agricultores do Sul do país, os produtores passaram a procurar outras alternativas tecnológicas, dentre as quais se destaca o plantio direto. Porém, neste período histórico o plantio direto era considerado inviável economicamente para os Cerrados, a não ser em uma situação de muito longo prazo (CUNHA, 1989). Já na década de 1990, o plantio direto apresentou uma redução em seus custos devido à queda do preço do herbicida dessecante, assim possibilitando sua utilização econômica devido sua aproximação com os custos da tecnologia convencional. No caso do milho o plantio direto chegou a apresentar custos de produção menores que a alternativa tradicional (RODRIGUES, 1999).

Este artigo tem o objetivo de valorar economicamente os impactos ambientais de tecnologias de plantio de soja e milho em região de cerrados. Pretende-se problematizar a relação entre a eficiência na combinação de insumos e seus custos privados com a geração das externalidades ambientais e seus custos sociais. A partir da mensuração dos impactos ambientais é possível através da análise custo-benefício comparar diferentes alternativas tecnológicas - plantio direto e plantio convencional - quanto sua eficiência econômica e eficácia social.

\section{Metodologia}

Para a valoração econômica do processo erosivo foi utilizado o método custo-reposição (efeitos internos e efeitos externos). Em que pese todos os limites da aplicação dos métodos de valoração ambiental, os mesmos são de grande utilidade para avaliação de impactos ambientais da produção agrícola. O Método Custo de Reposição (MCR) está baseado na reparação de algum dano ao recurso ambiental e o custo de reposição pode ser entendido como uma medida do seu benefício. PEARCE (1993) afirma que o MCR é freqüentemente utilizado como uma medida do dano causado. Essa abordagem é correta nas situações em que é possível ar- 
gumentar que a reparação do dano deve acontecer por causa de alguma restrição da sustentabilidade da produção agrícola no longo prazo.

O MCR será utilizado empiricamente a partir dos seguintes procedimentos metodológicos:

1. descrição das tecnologias de plantio a serem analisadas - plantio direto e plantio convencional - enfatizando suas características técnicas e econômicas;

2. análise das relações naturais entre causas e efeitos do processo de erosão agrícola causado pelo uso de tecnologias de plantio na região do Cerrado;

3. valoração econômica dos efeitos do processo erosivo no custo de reposição de nutrientes dos solos nas tecnologias de plantio abordadas;

4. valoração econômica dos efeitos do processo de assoreamento dos recursos hídricos nas tecnologias de plantio abordadas no custo de reposição para companhia de recursos hídricos.

Segundo CAMPANHOLA et alli (1997) pode-se adotar um enfoque simplificador e quantificar as externalidades ambientais negativas de acordo com a importância que o bem perdido ou deteriorado tem para o agrossistema. Neste caso, o custo da erosão seria dado pelo valor dos nutrientes contidos no solo que foi perdido, ou, em outros casos mais graves onde a área torna-se inapta para a agricultura, o custo é obtido pelo preço de mercado da área de terra afetada. Entretanto, este tipo de abordagem não mede os danos sobre outros bens e serviços ambientais, como por exemplo, perdas da biodiversidade e, também, não mede outros efeitos decorrentes do processo erosivo que afetam outras partes do ecossistema, como, por, exemplo, a qualidade dos recursos hídricos.

Para se realizar a valoração econômica dos efeitos do processo de erosão / sedimentação é necessária uma compreensão prévia dos impactos ambientais causados pelo agente degradador. O processo de erosão dos solos tem basicamente dois tipos de efeitos: internos e externos. Os efeitos internos estão associados com a perda da eficiência da produção agrícola associados com o processo erosivo. Nesse sentido, esses custos são absorvidos pelos próprios produtores rurais, aumentando assim seus custos de produção no médio e longo prazo. Já os efeitos externos são absorvidos por outros agentes econômicos que sofrem fundamentalmente com o processo de assoreamento dos 
recursos hídricos, sendo que estes custos não estão incluídos nos custos privados do produtor / degradador.

O MCR será aplicado para valorar os impactos ambientais do plantio de soja no município de Mineiros - GO. Esta é uma importante localidade produtora de soja da região dos Cerrados brasileiros e também é caracterizada por uma rica biodiversidade. No município localiza-se o Parque Nacional das Emas, que além de ser uma das mais ricas reservas brasileiras em recursos ambientais, tem em seus limites a nascente do Rio Araguaia. Este rio, juntamente com o Rio Tocantins, forma uma das mais relevantes Bacias Hidrográficas do país, representando suprimento de água para a população urbana e rural e fonte significante para desenvolvimento do turismo na região centro-norte do país.

\section{Resultados e Discussões}

\subsection{Evolução do plantio direto nos cerrados brasileiros}

Segundo LANDERS (1996), o plantio direto (PD) foi introduzido no país, em 1969, em Não-Me-Toque - RS, com um plantio experimental de sorgo. Em relação às técnicas convencionais de preparo e cultivo do solo, o PD apresenta práticas agronômicas inovadoras, que movimentam menos o solo e permitem um eficiente controle da erosão, pela manutenção de uma cobertura morta (palha) sobre o solo. A adoção do PD foi uma reação espontânea de agricultores que sentiram a falta de sustentabilidade econômica e física do sistema de plantio convencional, intensivamente mecanizado, e em função dos efeitos da erosão e do alto investimento em maquinário.

A técnica do plantio direto vem sendo utilizada por um maior número de produtores na região dos cerrados brasileiros com o decorrer do tempo. A partir da Tabela 1, pode-se constatar que no início dos anos 90 a área destinada para plantio direto nos cerrados brasileiros correspondia a $8,7 \%$ do total destinado em todo o Brasil. Já no final desta década subiu para $29,70 \%$. Nesse mesmo período, enquanto a área brasileira destinada para o plantio direto crescia 13,5 vezes, nos cerrados brasileiros cresceu cerca de 46 vezes. 
Tabela 1 - Evolução da área plantada em plantio direto (em ha)

\begin{tabular}{r|rr}
\hline Ano agrícola & Cerrados & Brasil \\
\hline $1974 / 75$ & - & 8.000 \\
$1976 / 77$ & - & 57.000 \\
$1978 / 79$ & - & 54.000 \\
$1980 / 81$ & - & 205.000 \\
$1982 / 83$ & 500 & 260.000 \\
$1984 / 85$ & 2.000 & 500.000 \\
$1986 / 87$ & 9.000 & $\mathrm{n} . \mathrm{d}$. \\
$1988 / 89$ & 35.000 & $\mathrm{n} . \mathrm{d}$. \\
$1990 / 91$ & 87.000 & 1.000 .000 \\
$1991 / 92$ & 180.000 & 1.350 .000 \\
$1992 / 93$ & 270.000 & $\mathrm{n} . \mathrm{d}$. \\
$1993 / 94$ & 420.000 & 3.000 .000 \\
$1994 / 95$ & 930.000 & 3.800 .000 \\
$1995 / 96$ & 1.500 .000 & 4.500 .000 \\
$1996 / 97$ & 1.938 .000 & 7.900 .000 \\
$1997 / 98$ & 2.670 .000 & 10.100 .000 \\
$1998 / 99$ & 3.402 .000 & 12.100 .000 \\
$1999 / 00$ & 4.000 .000 & 13.470 .000 \\
\hline
\end{tabular}

Fonte - Fundação ABC - Citada por LANDERS (1996), p. 14. FEBRAPD (2001).

Entre 1990/2000, houve uma expansão de $4.498 \%$ na área plantada nos cerrados com a utilização da tecnologia do plantio direto, em contrapartida com uma expansão de $1.247 \%$ na área plantada no Brasil (Tabela 1). Houve uma expansão considerável da utilização do plantio direto no Brasil, com particular destaque para região dos cerrados, por ser uma importante fronteira agrícola do país, com a exploração intensiva de commodities propícias à utilização desta tecnologia de plantio.

Outros fatores devem ser observados como elementos da mudança de comportamento dos produtores rurais na adoção de tecnologias com menor impacto ambiental. SAMAHA e LANDERS (1998), ressaltam que essas mudanças estão sendo condicionadas por uma crescente exigência social a respeito da qualidade ambiental.

Dessa forma, o plantio direto torna-se uma ferramenta importante para a busca da competitividade e da sustentabilidade da produção agrícola. Competitividade pois possibilita a maximização do lucro na propriedade rural no longo prazo, pela contenção do processo de erosão e sustentabilidade, pois esta tecnologia reduz os impactos ambientais causados pelo processo erosivo reduzindo o nível de externalidades ambientais negativas. 


\subsection{Efeitos internos do processo de erosão dos solos}

Os custos internos do processo de erosão devem ser calculados utilizando-se as perdas de solo por cultura transformadas em perdas de nutrientes conforme a composição do solo. Considera-se que toda a perda de terra representa também correspondente perda de nutrientes. Tem-se a seguinte equação de determinação dos custos internos (MARQUES, 1998):

Custos internos $=\mathbf{Q n}(\mathbf{P n}+\mathbf{C a})+(\mathbf{P p} * \mathbf{Q p})$, onde:

Qn = fertilizantes carreados pela erosão (tonelada);

$\mathrm{Pn}=$ preço dos fertilizantes $(\mathrm{R} \$)$;

$\mathrm{Ca}=$ custo de aplicação dos fertilizantes (R\$);

$\mathrm{Pp}=$ preço da produção agrícola (R\$);

$\mathrm{Qp}=$ redução da produtividade de longo prazo em virtude da erosão (ton./ha) ${ }^{2}$.

Verifica-se na Tabela 2 que o plantio convencional gera uma erosão $300,12 \%$ superior ao plantio direto, indicando que esta tecnologia é muito mais sustentável no que diz respeito exclusivamente ao manejo dos solos.

Tabela 2 - Grupos de culturas, área ocupada e perdas de solo no município de Mineiros - GO

\begin{tabular}{c|ccc}
\hline Produtos & $\begin{array}{c}\text { Área ocupada } \\
\text { (ha) } \mathbf{1}\end{array}$ & $\begin{array}{c}\text { Erosão no plantio } \\
\text { convencional (ton./ano) }{ }^{2}\end{array}$ & $\begin{array}{c}\text { Erosão no plantio direto } \\
\text { (ton./ano) }{ }^{2}\end{array}$ \\
\hline Soja & 44.864 & $215.347,20$ & $40.377,60$ \\
Milho & 8.672 & $29.484,80$ & $20.812,80$ \\
TOTAL & $\mathbf{5 5 . 5 3 6}$ & $\mathbf{2 4 4 . 8 3 2 , 0 0}$ & $\mathbf{6 1 . 1 9 0 , 4 0}$ \\
\hline
\end{tabular}

Fonte: ${ }^{1}$ IBGE - Censo Agropecuário (1995/1996); ${ }^{2}$ Cálculos feitos a partir de SATURNINO e LANDERS (1997); o arraste de partículas na soja plantio convencional é de 4,8 ton./ano e no plantio direto 0,9 ton./ano; no milho os indicadores para o plantio convencional e o plantio são respectivamente 3,4 ton./ano e 2,4 ton./ano.

Para se avaliar os efeitos do processo erosivo sobre a rentabilidade do produtor individual serão elaboradas duas hipóteses: 1) toda a produção de milho e soja no município de Mineiros - GO é feita através do plantio convencional (Tabela 3) e; 2) toda a produção de milho e soja é realizada pelo uso do plantio direto (Tabela 4).

\footnotetext{
${ }^{2}$ Neste trabalho não é considerada a perda de produtividade no longo prazo com a erosão. Por hipótese admite-se que toda a perda de nutrientes pode ser reposta.
} 
Utilizando-se o Método Custo-Reposição verifica-se na Tabela 3 que, se todos os produtores de milho e soja do município de Mineiros - GO, utilizarem a tecnologia tradicional, terão um custo anual com reposição de nutrientes de $R$ \$ 227.482,46, ou seja, um valor médio de $R$ \$ 4,10 por hectare.

Tabela 3 - Estimativa do valor econômico das perdas de solo no Plantio Convencional no município de Mineiros - GO

\begin{tabular}{|c|c|c|c|c|c|c|c|}
\hline Nutrientes & $\begin{array}{l}\text { Concentração } \\
\text { de nutrientes } \\
\text { no solo (\%) }\end{array}$ & $\begin{array}{c}\text { Perdas de } \\
\text { nutrientes } \\
\text { (ton.) }\end{array}$ & Fertilizantes & $\begin{array}{c}\text { Kg. Fert./kg } \\
\text { nutrientes }\end{array}$ & $\begin{array}{l}\text { Perdas de } \\
\text { fertilizantes } \\
\text { (ton./ano) }\end{array}$ & $\begin{array}{c}\text { Preço dos } \\
\text { fertilizantes } \\
\text { (R\$) }\end{array}$ & $\begin{array}{c}\text { Valor econômico } \\
\text { das perdas em } \\
\text { R / ano } \\
\end{array}$ \\
\hline Nitrogênio & 0,096750 & 236,87 & Uréia (45\% N) & 2,22 & 525,85 & 388,00 & $204.029,04$ \\
\hline Fósforo & 0,002614 & 6,40 & $\begin{array}{l}\text { Superfosfato } \\
\text { simples }\end{array}$ & 5,56 & 35,58 & 263,00 & $9.537,54$ \\
\hline Potássio & 0,010058 & 24,63 & $\begin{array}{l}\text { Cloreto de } \\
\text { potássio }\end{array}$ & 1,66 & 4,08 & 220,00 & 897,60 \\
\hline \multirow{2}{*}{$\begin{array}{l}\text { Cálcio + } \\
\text { Magnésio } \\
\text { Perdas do } \\
\text { solo em ton. }\end{array}$} & 0,094872 & 232,28 & $\begin{array}{l}\text { Calcário } \\
\text { dolomítico }\end{array}$ & 2,63 & 610,90 & 21,31 & $13.018,28$ \\
\hline & $244.832,00$ & & - & - & & - & $227.482,46$ \\
\hline
\end{tabular}

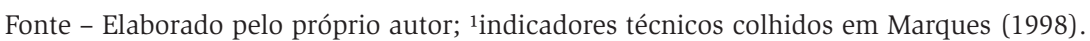

Por outro lado observa-se que, de acordo com a Tabela 4, se todos os produtores do município utilizarem a tecnologia do plantio direto teriam um custo médio com reposição de nutrientes de R $\$ 1,06$ por hectare, ou seja, um custo anual com reposição de nutrientes de $\mathrm{R} \$ 58.949,48$.

Tabela 4 - Estimativa do valor econômico das perdas de solo no Plantio Direto no município de Mineiros - GO

\begin{tabular}{|c|c|c|c|c|c|c|c|}
\hline Nutrientes & $\begin{array}{c}\text { Concentração } \\
\text { de nutrientes } \\
\text { no solo (\%) }\end{array}$ & $\begin{array}{l}\text { Perdas de } \\
\text { nutrientes } \\
\text { (ton.) }\end{array}$ & Fertilizantes & $\begin{array}{l}\text { Kg. Fert./kg } \\
\text { nutrientes }\end{array}$ & $\begin{array}{c}\text { Perdas de } \\
\text { fertilizantes } \\
\text { (ton./ano) }\end{array}$ & $\begin{array}{c}\text { Preço dos } \\
\text { fertilizantes } \\
\text { (R\$) } \\
\end{array}$ & $\begin{array}{c}\text { Valor econômico } \\
\text { das perdas em } \\
\mathrm{R} \$ \text { / ano } \\
\end{array}$ \\
\hline Nitrogênio & 0,096750 & 59,20 & Uréia (45\% N) & 2,22 & 131,42 & 388,00 & $50.992,51$ \\
\hline Fósforo & 0,002614 & 1,60 & $\begin{array}{l}\text { Superfosfato } \\
\text { simples }\end{array}$ & 5,56 & 8,90 & 263,00 & $2.340,70$ \\
\hline Potássio & 0,010058 & 6,47 & $\begin{array}{l}\text { Cloreto de } \\
\text { potássio }\end{array}$ & 1,66 & 10,74 & 220,00 & $2.362,84$ \\
\hline $\begin{array}{l}\text { Cálcio + } \\
\text { Magnésio }\end{array}$ & 0,094872 & 58,05 & $\begin{array}{l}\text { Calcário } \\
\text { dolomítico }\end{array}$ & 2,63 & 152,67 & 21,31 & $3.253,43$ \\
\hline $\begin{array}{l}\text { Perdas do } \\
\text { solo em ton. }\end{array}$ & $61.190,40$ & - & - & & - & & $58.949,48$ \\
\hline
\end{tabular}

Fonte - Elaborado pelo próprio autor; ${ }^{1}$ indicadores técnicos colhidos em Marques (1998).

Em uma abordagem comparativa dos custos anuais de reposição com nutrientes, verifica-se uma redução de $74,15 \%$ com adoção da tecnologia conservacionista (plantio direto). Entretanto, do ponto de vista econômico, 
em uma perspectiva de maximização de lucros no curto prazo, os produtores rurais podem preferir a alternativa de ocupar outras áreas na sua propriedade sem fazer o custo de reposição de nutrientes ou mesmo trocar a tecnologia de plantio. Nesse sentido, pode ocorrer o desmatamento das reservas florestais legais e das matas ciliares para o uso como lavouras.

\subsection{Efeitos externos: os custos do assoreamento para os sistemas de captação de água}

Como já foi destacado, existem vários efeitos externos associados ao processo de erosão, sendo o mais significativo o assoreamento dos recursos hídricos. O processo de assoreamento reduz a disposição de recursos hídricos para outros agentes econômicos que compartilham do mesmo recurso ambiental. Dessa forma o processo de erosão causa indiretamente, por exemplo, o aumento no custo de geração de energia elétrica, o aumento no custo da captação de água para o abastecimento urbano e pode reduzir a disposição de recursos hídricos para regiões que necessitam de projetos de irrigação. Nesse artigo a externalidade escolhida para a valoração econômica é constituído pelos efeitos econômicos do processo de erosão sobre o custo de captação de água no município de Mineiros - GO. A função física para a estimativa do total de sedimentos retidos nos córregos, rios e reservatórios é a seguinte (CHAVES ET ALII, 1995)³:

$\mathbf{R}=\mathbf{P} \cdot \mathbf{E} \cdot \mathbf{n} \cdot \mathbf{A} \cdot \mathbf{p}$

Onde:

$\mathrm{R}$ - volume de retenção de sedimentos nos recursos hídricos (ton./ano)

$\mathrm{P}$ - valor médio de perda do solo (\%)

E - taxa de entrega de sedimentos (\%)

n - eficiência média de retenção dos sedimentos nos recursos hídricos (\%)

A - área estimada pela ocupação de lavouras (ha)

p - volume do solo carreado para os recursos hídricos (\%)

${ }^{3}$ Citado por LANDERS, J. N. O plantio direto na agricultura: o caso do Cerrado. In LOPES, I V; BASTOS FILHO, G S; BILLER, BILLER, D. e BALE, M,. In Gestão ambiental no Brasil - experiência e sucesso. Rio de Janeiro: Editora Fundação Getúlio Vargas, 1994, p. 8-9. 
Ainda em uma perspectiva comparativa, nas Tabelas 5 e 6 têm-se para as culturas do milho e da soja, os seguintes indicadores para o plantio convencional e o plantio direto no município de Mineiros - GO:

Tabela 5 - Estimativa do custo social do assoreamento dos recursos hídricos com a utilização da tecnologia de plantio convencional no sistema de captação de água no município de Mineiros - GO

\begin{tabular}{c|cccccc}
\hline Cultura & R (ton./ano) & $\mathbf{P}^{\mathbf{1}}$ (ton./ano) & $\mathbf{E}^{\mathbf{2}} \mathbf{( \% )}$ & $\mathbf{P}^{\mathbf{2}}(\%)$ & $\mathbf{A}(\mathbf{h a})$ & $\mathbf{P}^{\mathbf{2}}(\%)$ \\
\hline Soja & $10.767,36$ & 4,8 & $50 \%$ & $50 \%$ & 44.864 & $20 \%$ \\
Milho & $1.474,24$ & 3,4 & $50 \%$ & $50 \%$ & 8.672 & $20 \%$ \\
TOTAL & $\mathbf{1 2 . 2 4 1 , 6 0}$ & - & - & - & - & - \\
\hline
\end{tabular}

Fonte - Elaborado pelo próprio autor; ${ }^{1}$ indicadores técnicos colhidos em SATURNINO e LANDERS (1997); 2 indicadores técnicos colhidos em (CHAVES ET ALII, 1995).

Tabela 6 - Estimativa do custo social do assoreamento dos recursos hídricos com a utilização da tecnologia de plantio direto no sistema de captação de água no município de Mineiros - GO

\begin{tabular}{|c|c|c|c|c|c|c|}
\hline Cultura & $R$ (ton./ano) $P^{1}$ & (ton./ano) & $\mathrm{E}^{2}(\%)$ & $P^{2}(\%)$ & A (ha) & $P^{2}(\%)$ \\
\hline Soja & $2.018,88$ & 0,9 & $50 \%$ & $50 \%$ & 44.864 & $20 \%$ \\
\hline Milho & $1.040,64$ & 2,4 & $50 \%$ & $50 \%$ & 8.672 & $20 \%$ \\
\hline TOTAL & $3.059,52$ & & & & & \\
\hline
\end{tabular}

Fonte - Elaborado pelo próprio autor; ${ }^{1}$ indicadores técnicos colhidos em SATURNINO e LANDERS (1997); 2 indicadores técnicos colhidos em (CHAVES ET ALII, 1995).

Considerando a hipótese de que todo o plantio de soja e milho é feito pelo método convencional (grade niveladora) o volume de retenção total estimada no município de Mineiros - GO é de 12.241,60 ton./ano. Medindo as externalidades causadas pelo processo de assoreamento sobre o sistema de captação de água, estima-se que o custo eventual de remoção do sedimento eqüivale a $\mathrm{R} \$ 7,33^{4}$. Desta forma pode-se calcular os custos ambientais do processo de erosão / assoreamento no município de Mineiros - GO sobre o sistema de captação de água em R\$ 89.730,93 /ano.

Considerando a hipótese de que todo o plantio de soja e milho é feito pelo plantio direto o volume de retenção total estimada no município de Mineiros - GO é de 3.059,52 ton./ano. Pode-se estimar os custos ambientais do processo de erosão / assoreamento no município de Mineiros - GO sobre o sistema de captação de água em R\$22.426,28 / ano.

\footnotetext{
${ }^{4}$ Valor estimado pela SABESP em U\$ 3,90 para a remoção de uma tonelada de sedimentos do fundo dos rios.
} 
A partir do somatório dos efeitos internos e externos do processo erosivo pode-se estimar que os danos ambientais causados pelo processo erosivo com a utilização do plantio convencional são de $\mathrm{R} \$ 317.213,39$ / ano, enquanto que se os produtores utilizarem a tecnologia do plantio direto estes mesmos danos serão de R\$ 81.375,76 / ano. Entretanto, os impactos ambientais derivados ao processo de erosão dos solos não estão relacionados apenas aos seus efeitos sobre o sistema de captação de água municipal e nem somente pelas perdas de nutriente dos solos. Por essa razão, pode-se inferir que o valor total dos danos ambientais , incluindo valores de opção, quase opção e de existência dos recursos ambientais, são bastante superiores. Também a diferença monetária entre a redução dos danos ambientais com a adoção da tecnologia do plantio direto também são bem mais elevadas.

\subsection{A análise custo - benefício social do plantio convencional e do plantio direto}

Para realizar a análise custo benefício social do plantio convencional e direto é necessário calcular o custo social médio, que agrega tanto o custo privado de produção quanto os custos ambientais gerados pelo processo erosivo. O custo social é estimado a partir do somatório dos custos de produção (privados) e dos efeitos do processo de erosão / sedimentação sobre a reposição dos nutrientes dos solos e dos efeitos da sedimentação dos recursos hídricos no sistema de captação de água (ambientais).

No caso da soja, a utilização do plantio convencional gera um custo social de R $\$ 422,53$ por hectare / ano, sendo $\mathrm{R} \$ 415,29$ de custo privado e $\mathrm{R} \$ 7,24$ de custo ambiental ( $\mathrm{R}$ 4,5 para a reposição de nutrientes do solo erodido e R \$ 1,72 para cobrir custos com a remoção dos sedimentos dos recursos hídricos). Já no plantio direto, o cultivo da soja gera um custo social de $\mathrm{R} \$ 418,59$ por hectare / ano, sendo $\mathrm{R} \$ 417,23$ de custo privado e $\mathrm{R}$ \$ 1,36 de custo ambiental ( $\mathrm{R}$ \$ 0,61 para a reposição de nutrientes e R \$ 0,69 para a remoção de sedimentos dos recursos hídricos) (Gráfico 1). 
GRÁFICO 1 - SOJA: COMPARAÇÃO DOS CUSTOS SOCIAIS NO PLANTIO DIRETO E CONVENCIONAL

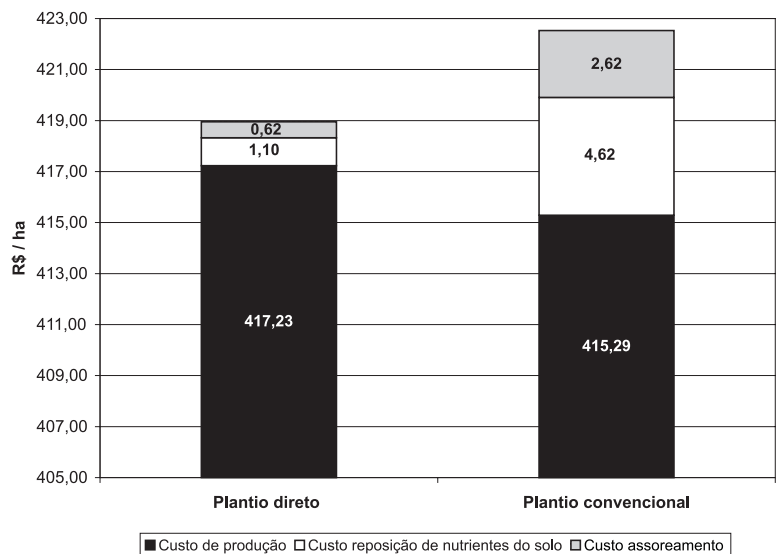

Fonte - Elaboração própria.

Observa-se que enquanto os custos de produção da soja são superiores no plantio direto em $0,47 \%$, ao adicionar-se os custos ambientais de reposição de nutrientes do solo o plantio direto passa a ter um custo $(-0,37 \%)$ menor (Gráfico 1). Este indicador demonstra que na medida que as terras aptas para atividade agrícola são utilizadas na fazenda, o produtor sente-se impelido a adotar práticas mais sustentáveis de cultivo (plantio direto), pois o seu custo de reposição é menor. Isso explica, em parte, a grande aceitação do plantio direto em áreas de Cerrado, com uma adesão cada vez maior de produtores. Os custos ambientais, a médio e longo prazos, podem incorrer no próprio aumento do custo de produção, na perda da competitividade, levando o produtor a buscar alternativas de plantio mais sustentáveis do ponto do vista dos solos.

No caso do milho, a utilização do plantio convencional gera um custo social de $\mathrm{R} \$ 487,39$ por hectare / ano, sendo $\mathrm{R} \$ 487,39$ de custo privado e $\mathrm{R} \$ 5,13$ de custo ambiental ( $\mathrm{R} \$ 3,16$ para a reposição de nutrientes do solo erodido e R $\$ 1,25$ para cobrir custos com a remoção dos sedimentos dos recursos hídricos). Já no plantio direto, o cultivo de milho gera um custo social de $\mathrm{R} \$ 458,51$ por hectare / ano, sendo $\mathrm{R} \$ 458,51$ de custo privado e $\mathrm{R} \$ 3,62$ de custo ambiental ( $\mathrm{R} \$ 2,30$ para a reposição de nutrientes e $\mathrm{R} \$ 0,32$ para a remoção de sedimentos dos recursos hídricos) (Gráfico 2). 
GRÁFICO 2- MILHO: COMPARAÇÃO DOS CUSTOS SOCIAIS DO PLANTIO CONVENCIONAL E DIRETO

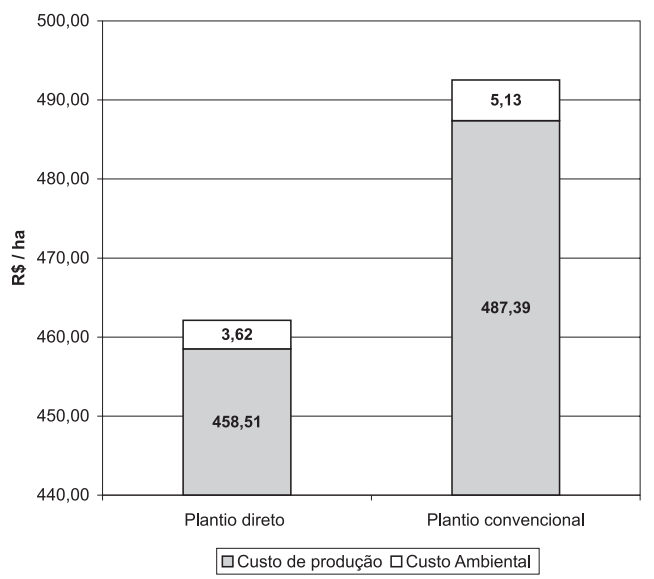

Fonte - Elaboração própria.

No caso do milho, o plantio direto tem uma clara vantagem sobre o plantio convencional, tanto em custos privados e sociais. Com a adoção do plantio direto tem-se uma redução de $(-5,93 \%)$ no custo de produção, $(-29,43 \%)$ no custo ambiental e $(-6,37 \%)$ no custo social (Gráfico 2).

Após os cálculos dos custos sociais é possível realizar análise custobenefício social, que incorpora, simultaneamente, os custos privados e os custos ambientais nos cultivos da soja e do milho utilizando plantio direto e convencional. No caso da soja, a adoção do plantio direto gera um valor presente líquido social $1,38 \%$ e uma taxa interna de retorno descontada social anual 0,29\% maiores do que no caso do plantio convencional (Tabela 7). 
Tabela 7 - Análise dos custos sociais do processo erosivo na produção de soja/ha/ano

\begin{tabular}{|c|c|c|c|c|}
\hline \multirow[t]{2}{*}{ ANOS } & \multicolumn{2}{|c|}{ PLANTIO DIRETO } & \multicolumn{2}{|c|}{ PLANTIO CONVENCIONAL } \\
\hline & CUSTOS $^{2}$ & BENEFÍCIOS & CUSTOS$^{2}$ & BENEFÍCIOS \\
\hline 0 & $-188,60$ & & $-204,20$ & \\
\hline 1 a 10 & 435,96 & 566,67 & 422,53 & 566,67 \\
\hline TOTAL DO FLUXO & $4.220,64$ & $5.666,70$ & $4.225,30$ & $5.666,70$ \\
\hline $\begin{array}{l}\text { TOTAL DO FLUXO } \\
\text { DESCONTADO }^{1}\end{array}$ & 1875,26 & 2502,07 & 1865,63 & 2502,07 \\
\hline B/C SOCIAL & 1,33 & 425 & 1,34 & \\
\hline VPL SOCIAL & 438 & & 432 & \\
\hline $\begin{array}{l}\text { TIR DESCONTADA } \\
\text { SOCIAL - } 10 \text { ANOS } \\
\text { (TIRdescsoc10anos) }\end{array}$ & 45,2 & $0 \%$ & 43,6 & \\
\hline $\begin{array}{l}\text { TIR DESCONTADA } \\
\text { SOCIAL ANUAL } \\
\text { (TIRdescsocano) }\end{array}$ & 3,8 & & 3,6 & \\
\hline
\end{tabular}

Fonte - Elaboração própria.

${ }^{1}$ Total dos fluxos de caixa descontado a uma taxa de 18,5\% (OVER-SELIC julho / 2002)

${ }^{2}$ a partir do $3^{\circ}$ ano há queda de $2,6 \%$ nos custos do plantio direto (LANDERS, 1996).

Olhando apenas os custos e benefícios privados na produção da soja, os indicadores econômicos apontaram para a vantagem da adoção no plantio convencional. Entretanto, com a soma dos custos ambientais envolvidos nas duas tecnologias de plantio, a situação inverte-se. Ficando o plantio direto com melhores indicadores de viabilidade. $\mathrm{Na}$ produção da soja quais variáveis, ou condições específicas, implicam nessa alteração das condições de viabilidade econômica e ambiental destas tecnologias de plantio?

No caso do milho, a adoção do plantio direto gera um valor presente líquido social 299,68\% e uma taxa interna de retorno descontada social anual 1,19\% maiores do que no caso do plantio convencional (Tabela 8). 
Tabela 8 - Análise dos custos sociais do processo erosivo na produção de milho/ha/ano

\begin{tabular}{|c|c|c|c|c|}
\hline \multirow[t]{2}{*}{ ANOS } & \multicolumn{2}{|c|}{ PLANTIO DIRETO } & \multicolumn{2}{|c|}{ PLANTIO CONVENCIONAL } \\
\hline & CUSTOS $^{2}$ & BENEFÍCIOS & CUSTOS $^{2}$ & BENEFÍCIOS \\
\hline 0 & $-188,60$ & & $-204,20$ & \\
\hline 1 a 10 & 471,64 & 564,34 & 418,56 & 564,34 \\
\hline TOTAL DO FLUXO & $4.618,32$ & $5.643,40$ & $4.185,60$ & $5.643,40$ \\
\hline $\begin{array}{l}\text { TOTAL DO FLUXO } \\
\text { DESCONTADO }^{1}\end{array}$ & 2047,42 & 2491,78 & 1848,10 & 2491,78 \\
\hline $\mathrm{B} / \mathrm{C}$ & \multicolumn{2}{|c|}{1,31069} & \multicolumn{2}{|c|}{1,14582} \\
\hline VPL & \multicolumn{2}{|c|}{451,28} & \multicolumn{2}{|c|}{112,91} \\
\hline $\begin{array}{l}\text { TIR DESCONTADA - } 10 \\
\text { ANOS (TIRdesc10anos) }\end{array}$ & \multicolumn{2}{|c|}{$26,27 \%$} & \multicolumn{2}{|c|}{$12,37 \%$} \\
\hline TIR ANUAL & \multicolumn{2}{|c|}{$2,36 \%$} & \multicolumn{2}{|c|}{$1,17 \%$} \\
\hline
\end{tabular}

Fonte - Elaboração própria.

${ }^{1}$ Total dos fluxos de caixa descontado a uma taxa de 18,5\% (OVER-SELIC julho / 2002)

2 a partir do $3^{\circ}$ ano há queda de $2,6 \%$ nos custos do plantio direto (LANDERS, 1996).

O que se pode concluir em termos de análise custo-benefício que além da tecnologia do plantio direto ser mais eficiente do ponto de vista econômico no caso do milho, tem um custo de produção relativamente superior no caso da soja. Entretanto, o plantio direto gera um benefício social líquido na medida que reduz o impacto da erosão sobre a sedimentação dos recursos hídricos reduzindo as externalidades ambientais negativas. Isto afeta positivamente o bem-estar dos outros agentes econômicos que dependem do mesmo recurso ambiental, podendo justificar a intervenção do poder público, através de instrumentos de gestão econômica do meio ambiente - para estimular a adoção da tecnologia tida como mais conservacionista.

No caso do milho, sendo a tecnologia do plantio direto mais eficiente economicamente do que o plantio convencional não há razão para o poder público elaborar instrumentos de gestão econômica do meio ambiente (subsídios) para estimular a adoção da tecnologia considerada conservacionista, pois neste caso apenas os mecanismos de mercado são suficientes. Entretanto, recomenda-se como sendo responsabilidade do poder público a promoção de programas para a disseminação da tecnologia agrícola menos agressiva ao meio ambiente.

Na cultura do milho, com a utilização do plantio direto, houve a feliz coincidência de que a tecnologia menos agressiva ao meio ambiente 
também é a mais eficiente do ponto de vista econômico. Entretanto isso só foi possível porque os produtores rurais começaram a sentir os efeitos da erosão sobre seus níveis de lucratividade e houve um acentuado investimento em pesquisa agropecuária por parte do governo e entidades de classe para o aperfeiçoamento desta técnica de plantio.

No caso da soja, a tecnologia do plantio convencional apresentou custos de produção menores do que o plantio direto, entretanto com a consideração dos custos com reposição de nutrientes, o plantio direto já passa a apresentar vantagens econômicas. Também, neste caso, é imprescindível que o poder público juntamente com as organizações dos produtores rurais, disseminem o plantio direto para ampliar sua utilização, levando-se em conta a necessidade de treinamento dos produtores rurais para o correto manejo dos herbicidas a fim de evitar acidentes de trabalho e o agravamento dos impactos ambientais desta tecnologia. Outro papel fundamental a ser desempenhado pelo poder público, é o fomento a pesquisas agronômicas que visem a aperfeiçoar o plantio direto, principalmente na redução do uso de herbicidas no seu manejo, reduzindo assim possíveis contaminações de cursos de água.

\section{Considerações Finais}

O plantio direto é uma tecnologia em plena expansão nos Cerrados brasileiros. Nos últimos anos, o plantio direto vem tendo grandes evoluções em termos de eficiência econômica através do esforço do institutos de pesquisa do governo, de grandes empresas multinacionais à montante e das associações dos produtores, onde os herbicidas dessecantes vem tendo seus preços reduzidos e as técnicas de manejo estão sendo difundidas em larga escala. Em termos ambientais a técnica do plantio direto apresenta várias vantagens, principalmente, associadas com a redução do processo de erosão dos solos e assoreamento dos recursos hídricos.

No caso da soja a adoção do plantio direto eleva o custo de produção em $0,47 \%$, mas com a adição do custo de reposição de nutrientes do solo este custo passa a ser $(-0,37 \%)$ menor do que no plantio convencional. Isso comprova que em uma situação de longo prazo o plantio direto já é uma alternativa econômica mais atraente do que o plantio convencional, na medida em que áreas vão sendo praticamente inutilizadas para a ex- 
ploração econômica em propriedades que utilizam métodos convencionais de cultivo. Ainda, com a posterior adição do custo de remoção de sedimentos de recursos hídricos, o custo social passa a ser $(-0,93 \%)$ menor do que no plantio convencional. Ademais, foi verificada uma redução de $(-81,22 \%)$ no custo ambiental com a adoção do plantio direto, ficando assim demonstrado a maior sustentabilidade desta tecnologia de plantio. No cultivo do milho, os custos de produção do plantio direto são $(-5,92 \%)$ menores do que os referentes ao plantio convencional, demostrando sua maior eficiência econômica. Ademais, a adoção do plantio direto reduz o custo ambiental em $(-29,43 \%)$ e o custo social em (-6,17\%).

Pelos danos medidos nas duas tecnologias de plantio ficou evidenciado que os impactos ambientais do plantio direto são bem menores do que o plantio convencional. A adoção do plantio direto somente no município de Mineiros (GO) representaria uma redução nos danos ambientais sobre a reposição de nutrientes e no assoreamento dos recursos hídricos em aproximadamente $\mathrm{R} \$ 235.837,63$ ao ano, excetuando outras externalidades ambientais não mensuradas e desconsiderando a (quase) irreversibilidade de vários impactos ambientais causados pela erosão dos solos, como a inépcia completa dos solos para qualquer uso econômico ou natural e a perda de vazão e da qualidade dos recursos hídricos.

\section{Referências Bibliográficas}

APG-Mineiros. Custo médio de produção do milho e da soja no plantio convencional e plantio direto. Mineiros: 1999 (mimeo)

CAMPANHOLA,C.L.; Alfredo J.; RODRIGUES, G.S. Agricultura e impacto ambiental. I Simpósio sobre os Cerrados do Meio-norte. Teresina, 09, a 12 dez., 1997 (Embrapa),159-168.

CHAVES,H.M.L. Efeitos do plantio direto sobre o meio ambiente. In: SATURNINO,H.M.;LANDERS,J.N. O meio ambiente e o plantio direto. Goiânia: 1997. p.57-66.

COLOZZI NETO, F A . Solo sob plantio direto. Londrina: EMBRAPA, 1997. 235p.

CUNHA, A. S. (coord.) Uma Avaliação da Sustentabilidade da Agricultura nos Cerrados. Relatórios de Pesquisa, Brasília. IPEA, fev. İ994. 256 p. 
CUNHA ,G. Plantio direto. 39.ed. São Paulo: IEA, 1997. 28p.

DAROLT, M.R. Plantio direto: pequenas propriedades sustentáveis. Londrina: IAPAR, 1998. 255p.

EATON, B. C. e EATON, D. F. Microeconomia. São Paulo: Saraiva, 1999. $606 \mathrm{p}$.

ERVIN, C. e ERVIN, D. - 1982. Factors affecting the use of soil conservation practices: Hypotheses, evidence and policy implications. Lands Economics, Vol 58, NE pp. 277-292.

FAEG. Produção e custo de produção do milho e da soja. Goiânia: 1999. (mimeo)

FIELD, Barry C. Economía Ambiental - Uma Introducción - Colômbia, McGrawHill, 1995. 587 p.

HIRCHFELD, H. Engenharia econômica e análise de custos. São Paulo: Atlas, 1989. p. 151-164.

LANDERS, J.N.; TEIXEIRA, S,M.;MILHOMEN, A. Possíveis impactos técnica de plantio direto sobre a sustentabilidade da produção de grãos nos Cerrados In: $3^{\circ}$ Congresso Brasileiro de Economia e Sociologia Rural. 1994, p.199-813.

LANDERS,J.N. O plantio direto na agricultura: o caso do Cerrado. In: LOPES, Ignez V.; FILHO, Guilherine S.B.; BTLLER, Dan; BALE, Malcolm. Gestão Ambiental no Brasil. Rio de Janeiro, 1996, p.4-24.

LUTZ, E., PAGIOLA, S e REICH, C. The costs and benefits of soil conservacion: the farmers viewpoint. In: The World Bank Research Observer, vol. 9, no 2 (july, 1994), p. 273-95.

MARQUES, João Fernando. Custos da erosão do solo em razão dos efeitos internos e externos à área da produção agrícola. In: Revista de Economia e Sociologia Rural, vol. 36, n⿳0 1, jan. / mar. Brasília: SOBER, 1998.

MCCONNELL K., 1983. An economic model of soil conservation. In: American Journal of Agricultural Economics, Vol. NE. pp. 83-89.

MUELLER,C.C. Centro-Oeste: Evolução, Situação Atual e Perspectivas de Desenvolvimento Sustentável. In: VELLOSO,J. R. (org.). Fórum Nacional como Evitar uma Nova "Década Perdida" A Ecologia e o Novo Padrão de Desenvolvimento no Brasil. Rio de Janeiro, 1991, p.88-125. 
De grão em grão o Cerrado perde o espaço. Brasília:

WWF, 2001.

MUZILLI, O . Atualização em plantio direto. In: FRANCIELI, A L.; VIDAL ,P. Plantio direto no Brasil. Campinas: CARGILL, 1985. p. 3-53.

NOGUEIRA, Jorge M. e Marcelino A. A. de MEDEIROS. "Quanto vale aquilo que não tem valor? Valor de existência, economia e meio ambiente". XXV Encontro Brasileiro de Economia (ANPEC). Recife, dezembro, 1997, 20p.

PAGIOLA S., 1993. Soil conservation and the sustainability of agricultural production. Dissertation submitted to the Food Research Institute and the Committee on Graduate Studies of Sanford University, in partial fulfillment of the requirements for degree of Doctor of Philosophy.

PYNDICK, Robert e RUBINFELD, D. L. Microeconomia. São Paulo, Makron Books, 1994. 968 p.

RODRIGUES, Waldecy. Avaliação econômica dos impactos econômicos da produção agrícola nos Cerrados brasileiros. In: $37^{\circ}$ Congresso Brasileiro de Economia e Sociologia Rural. 1999.

ROMANO, P.A. Plantio direto e recursos hídricos. In: SATURNINO,H. M; LANDERS J.N. O meio ambiente e o plantio direto . Goiânia: 1997. p.75-82.

SATURNINO,H. M; LANDERS J.N. O meio ambiente e o plantio direto. Goiânia: EMBRAPA, 1997. 116 p.

SAMAHA, H M; LANDERS, J N. A economia do plantio direto. In: DAROLT, M.R. Plantio direto: pequenas propriedades sustentáveis. Londrina: IAPAR, 1998. 255p.

SERÔA DA MOTTA, R. Análise de custo-benefício do meio ambiente. In: Margulis, S. Meio Ambiente: aspectos teóricos e econômicos. Rio de Janeiro, IPEA: Brasília, IPEA/PNUD, 1999. p. 109-134.

SHIKI,S. Sistema agroalimentar no Cerrado brasileiro: caminhado para o caos? In: SHIKI, S.; SILVA, J. Graziano. Agricultura, meio ambiente e sustentabilidade do Cerrado brasileiro. Uberlândia, 1997, p,101-152.

VASCONCELLOS M. A . S. e OLIVEIRA, R G. Manual de microeconomia. São Paulo: Atlas, 2000. 327 p. 